\title{
Framework and Extraframework Tin Sites in Zeolite Beta React Glucose Differently
}

\author{
Ricardo Bermejo-Deval, ${ }^{\dagger}$ Rajamani Gounder, ${ }^{\dagger}$ and Mark E. Davis* \\ Chemical Engineering, California Institute of Technology, Pasadena, California 91125, United States
}

Supporting Information

ABSTRACT: Here, we show that framework tin sites in pure silica zeolite Beta (Sn-Beta) can isomerize glucose to fructose by a Lewis acid-mediated intramolecular hydride shift in aqueous solvent, but not in methanol solvent. Mechanistic studies using isotopically labeled $\left({ }^{2} \mathrm{H},{ }^{13} \mathrm{C}\right)$ glucose reactants show that in methanol, Sn-Beta instead epimerizes glucose to mannose by a Lewis acid-mediated intramolecular carbon shift mechanism known as the Bilik reaction. We also provide evidence that extraframework tin sites located within the hydrophobic channels of zeolite Beta can isomerize glucose to fructose in both water and methanol solvent, but through a base-catalyzed proton-transfer mechanism. $\mathrm{SnO}_{2}$ particles located at external zeolite crystal surfaces or supported on amorphous silica catalyze isomerization in methanol but not in water, suggesting that contact with bulk water inhibits isomerization at $\mathrm{SnO}_{2}$ surfaces. ${ }^{119} \mathrm{Sn}$ MAS NMR spectroscopy was used to unambiguously identify framework Sn sites, which give resonances for octahedral Sn $(-685$ to $-700 \mathrm{ppm})$ in hydrated Sn-Beta that disappear upon dehydration, with the concomitant appearance of resonances for tetrahedral $\mathrm{Sn}(-425$ to $-445 \mathrm{ppm})$. In sharp contrast, spectra of hydrated samples containing extraframework $\mathrm{SnO}_{2}$ show resonances for octahedral $\mathrm{Sn}$ centered at $-604 \mathrm{ppm}$ that do not change upon dehydration. These findings demonstrate that aldose-ketose isomerization reactivity on Sn-zeolite samples cannot be ascribed to the presence of framework Sn sites in the absence of isotopic labeling studies. They also indicate that any Sn-zeolite samples that initially convert glucose to fructose, instead of mannose, in methanol solvent contain Sn species that are structurally different from framework Sn centers.

KEYWORDS: Bilik reaction, epimerization, glucose, isomerization, mannose, methanol, tin-Beta, water

\section{INTRODUCTION}

The conversion of molecules containing carbonyl functional groups, notably ring-opened forms of biomass-derived aldose and ketose sugars, using porous solids containing Lewis acidic centers has received considerable attention. ${ }^{1}$ Corma et al. initially reported that framework tin centers in zeolite Beta behave as Lewis acids that catalyze the Baeyer-Villiger oxidation and the Meerwein-Ponndorf-Verley (MPV) reduction of carbonyl compounds in organic solvents. ${ }^{2-4}$ More recently, $\mathrm{Sn}$ and $\mathrm{Ti}$ zeolites have been reported to catalyze aldose-ketose isomerization of glucose ${ }^{5-8}$ (to fructose) and $\mathrm{C}_{3}-\mathrm{C}_{5}$ sugars ${ }^{9,10}$ in aqueous media. Aldose epimerization products have also been observed with Sn-Beta catalysts for glucose $^{5,9}$ (to mannose) and xylose ${ }^{10}$ (to lyxose) reactants in aqueous media. The mechanistic details of glucose epimerization on Sn-Beta were not investigated previously, but xylose epimerization to lyxose was proposed to occur via a reversible intramolecular hydride shift that involved an common intermediate with the pathway for xylose isomerization to xylulose. ${ }^{10}$ Framework Sn centers in Sn-Beta have also been implicated as active sites that isomerize glucose and other sugars in organic solvents, such as methanol ${ }^{11-13}$ and ethanol. ${ }^{14}$

In aqueous media, we have shown previously that framework Sn centers behave as Lewis acids that bind glucose reactants in their acyclic forms and mediate their isomerization to fructose via an intramolecular hydride shift from the C-2 to the C-1 position. ${ }^{6,8}$ Glucose reactants containing a deuterium label on the C-2 position (glucose-D2) formed fructose products deuterated in the $\mathrm{C}-1$ position (fructose-D1), ${ }^{6,8}$ reflected in ${ }^{13} \mathrm{C}$ NMR spectra that showed low-intensity triplet resonances corresponding to these carbon atoms. Low-intensity resonances in ${ }^{13} \mathrm{C}$ NMR spectra acquired using ${ }^{1} \mathrm{H}$ broadband decoupling reflect the presence of $\mathrm{D}$ atoms that disrupt the nuclear Overhauser enhancement (NOE) of ${ }^{13} \mathrm{C}$ resonances via suppression of ${ }^{13} \mathrm{C}-{ }^{1} \mathrm{H}$ couplings. The mechanistic evidence obtained from ${ }^{13} \mathrm{C}$ and ${ }^{1} \mathrm{H}$ NMR studies were also consistent with the observed kinetic isotope effect of $\sim 2$ (at $383 \mathrm{~K}$ ) when using glucose-D2 reactants. ${ }^{8}$ Activation energies measured experimentally $\left(89 \mathrm{~kJ} \mathrm{~mol}^{-1}\right)$ and calculated by MP2-levels of theory for intramolecular hydride shift steps on framework Sn open sites ( $\mathrm{Sn}$ with three $-\mathrm{O}(\mathrm{Si})$ bonds and one $-\mathrm{OH}$ group) adjacent to one silanol group $\left(92 \mathrm{~kJ} \mathrm{~mol}^{-1}\right)$ were also similar. These Lewis acid-mediated isomerization pathways on Sn-Beta in aqueous solvent are analogous to those on metalloenzymes,

Received: July 16, 2012

Revised: October 23, 2012

Published: October 29, 2012 
such as D-xylose isomerase $\mathrm{XI}$, which contains two divalent metal ions (commonly $\mathrm{Mg}^{2+}$ or $\mathrm{Mn}^{2+}$ ) that facilitate the ringopening of glucose and the hydride shift from the C-2 to the C1 positions on the acyclic sugar. ${ }^{15}$

In contrast with the case of glucose isomerization to fructose on framework $\mathrm{Sn}$ sites in water, the mechanistic origins of glucose isomerization in methanol and glucose epimerization in either water or methanol remain unclear. Here, we use kinetic and mechanistic studies, focusing on differential glucose conversions and the primary products formed, to distinguish among isomerization and epimerization pathways on framework and extraframework Sn sites in zeolite Beta in both water and methanol. These data show that framework Sn sites behave as Lewis acids that isomerize glucose to fructose in water via intramolecular hydride shifts, but instead epimerize glucose to mannose in methanol via intramolecular carbon shifts. In contrast, extraframework $\mathrm{SnO}_{2}$ domains located within hydrophobic zeolite Beta channels mediate glucose isomerization to fructose via base-catalyzed proton abstraction in both water and methanol. Extraframework $\mathrm{SnO}_{2}$ particles located on external zeolite surfaces or on amorphous supports, however, isomerize glucose to fructose in methanol but not in water. These findings help clarify differences in reactivity among $\mathrm{Sn}$ sites of different structure and among extraframework $\mathrm{SnO}_{2}$ particles of different locations within porous solids. They also provide evidence for the mechanism of glucose epimerization to mannose with framework Sn-Beta and for a new pathway for glucose isomerization to fructose with $\mathrm{Sn}$-containing silicates in methanol solvent.

\section{EXPERIMENTAL METHODS}

2.1. Synthesis of Si-Beta, Sn-Beta, $\mathrm{SnO}_{2} / \mathrm{Si}-\mathrm{Beta}$, and $\mathrm{SnO}_{2}-\mathrm{SiO}_{2}$. Si-Beta was prepared by adding $10.01 \mathrm{~g}$ of tetraethylammonium flouride dihydrate (Sigma-Aldrich, 97\% (w/w) purity) to $10 \mathrm{~g}$ of water and $4.947 \mathrm{~g}$ of tetraethylorthosilicate (Sigma-Aldrich, 98\% (w/w)). This mixture was stirred overnight at room temperature in a closed vessel to ensure complete hydrolysis of the tetraethylorthosilicate. The targeted $\mathrm{H}_{2} \mathrm{O} / \mathrm{SiO}_{2}$ ratio was reached by complete evaporation of the ethanol and partial evaporation of the water. The final molar composition of the gel was $\mathrm{SiO}_{2} / 0.55 \mathrm{TEAF} /$ $7.25 \mathrm{H}_{2} \mathrm{O}$. The gel was transferred to a Teflon-lined stainless steel autoclave and heated at $413 \mathrm{~K}$ in a rotation oven $(60 \mathrm{rpm})$ for 7 days. The solids were recovered by filtration, washed extensively with water, and dried at $373 \mathrm{~K}$ overnight. The dried solids were calcined in flowing air $\left(1.67 \mathrm{~cm}^{3} \mathrm{~s}^{-1}\right.$, Air Liquide, breathing grade $)$ at $853 \mathrm{~K}\left(0.0167 \mathrm{~K} \mathrm{~s}^{-1}\right)$ for $10 \mathrm{~h}$ to remove the organic content located in the crystalline material.

Sn-Beta was synthesized according to previously reported procedures. ${ }^{8}$ A $7.57 \mathrm{~g}$ portion of tetraethylammonium hydroxide solution (Sigma-Aldrich, 35\% (w/w) in water) was added to $7.011 \mathrm{~g}$ of tetraethylorthosilicate (Sigma-Aldrich, 98\% $(\mathrm{w} / \mathrm{w})$ ), followed by the addition of $0.121 \mathrm{~g}$ of $\operatorname{tin}(\mathrm{IV})$ chloride pentahydrate (Sigma-Aldrich, 98\% (w/w)). The mixture was stirred until tetraethylorthosilicate was completely hydrolyzed and then allowed to reach the targeted $\mathrm{H}_{2} \mathrm{O} / \mathrm{SiO}_{2}$ ratio by complete evaporation of ethanol and partial evaporation of water. Finally, $0.690 \mathrm{~g}$ of HF solution (Mallinckrodt, 52\% (w/ w) in water) was added, resulting in the formation of a thick gel. The final molar composition of the gel was $1 \mathrm{SiO}_{2} / 0.01$ $\mathrm{SnCl}_{4} / 0.55 \mathrm{TEAOH} / 0.54 \mathrm{HF} / 7.52 \mathrm{H}_{2} \mathrm{O}$. Si-Beta was added as seed material ( 5 wt $\%$ of $\mathrm{SiO}_{2}$ in gel) to this gel and mixed. The final gel was transferred to a Teflon-lined stainless steel autoclave and heated at $413 \mathrm{~K}$ in a static oven for 40 days. The solids were recovered, washed, dried, and calcined using the procedure described above for Si-Beta.

$\mathrm{Si}$-Beta containing extraframework $\mathrm{SnO}_{2}\left(\mathrm{SnO}_{2} / \mathrm{Si}\right.$-Beta $)$ was prepared using the same procedure as $\mathrm{Sn}$-Beta, but with substitution of tin(IV) chloride pentahydrate with $0.052 \mathrm{~g}$ of tin(IV) dioxide (Sigma-Aldrich, -325 mesh; aggregate particle size $<44 \mu \mathrm{m}$ ) as the source of tin in the synthesis gel. The gel was transferred to a Teflon-lined stainless steel autoclave and heated at $413 \mathrm{~K}$ in a static oven for 25 days. The recovered solids were washed, dried, and calcined using the same procedure as for Si-Beta and Sn-Beta.

Si-Beta containing extraframework $\mathrm{SnO}_{2}$ particles located on external crystallite surfaces $\left(\mathrm{SnO}_{2} / \mathrm{Si}\right.$-Beta-E) was synthesized by first adding $0.059 \mathrm{~g}$ of tin(IV) chloride pentahydrate (SigmaAldrich, $98 \%(\mathrm{w} / \mathrm{w}))$ to $10 \mathrm{~g}$ of water. This solution was stirred with $1.0 \mathrm{~g}$ of Si-Beta in its as-made form for $16 \mathrm{~h}$ at ambient temperature. The solids were recovered by centrifugation and dried at $373 \mathrm{~K}$ overnight. Finally, the dried solids were calcined in flowing air $\left(1.67 \mathrm{~cm}^{3} \mathrm{~s}^{-1}\right.$, Air Liquide, breathing grade) at $853 \mathrm{~K}\left(0.0167 \mathrm{~K} \mathrm{~s}^{-1}\right)$ for $10 \mathrm{~h}$.

$\mathrm{SnO}_{2}$ was dispersed on silica $\left(\mathrm{SnO}_{2} / \mathrm{SiO}_{2}\right)$ by first adding 0.5 $\mathrm{g}$ of tin(IV) chloride pentahydrate (Sigma-Aldrich, $98 \%$ (w/ $\mathrm{w})$ ) to $30 \mathrm{~g}$ of water. Two grams of fumed silica (SigmaAldrich, $0.2-0.3 \mathrm{~mm}$ average particle size) was added to the mixture and stirred for $24 \mathrm{~h}$ at room temperature. The solids were recovered, washed, dried, and calcined using the same procedure as for crystalline zeolites.

2.2. Characterization Methods. Atomic $\mathrm{Si}$ and $\mathrm{Sn}$ contents were determined using a JEOL 8200 electron microprobe operated at $15 \mathrm{kV}$ and $25 \mathrm{nA}$ in a focused beam mode with a $40 \mu \mathrm{m}$ spot size. Scanning electron microscopy (SEM) images were recorded on a LEO $1550 \mathrm{VP}$ field emission SEM at an electron high tension of $10 \mathrm{kV}$ on zeolite samples after sputtering with carbon to minimize the effects of charging. The crystalline structures of zeolite samples were determined from powder X-ray diffraction (XRD) patterns collected using a Rigaku Miniflex II diffractometer and $\mathrm{Cu} \mathrm{K} \alpha$ radiation. Diffuse reflectance UV-visible (DRUV) spectra were recorded using a Cary $3 \mathrm{G}$ spectrophotometer equipped with a diffuse reflectance cell; zeolite samples were calcined in air at $853 \mathrm{~K}$ for $10 \mathrm{~h}$ and exposed to ambient conditions prior to acquiring spectra.

$\mathrm{N}_{2}$ adsorption isotherms at $77 \mathrm{~K}$ were obtained using a Quantachrome Autosorb iQ automated gas sorption analyzer. Zeolite samples (typically $0.03-0.04 \mathrm{~g}$ ) were pelleted and sieved to retain $150-600 \mu \mathrm{m}$ particles. Samples were degassed at $353 \mathrm{~K}\left(0.167 \mathrm{~K} \mathrm{~s}^{-1}\right)$ for $1 \mathrm{~h}, 393 \mathrm{~K}\left(0.167 \mathrm{~K} \mathrm{~s}^{-1}\right)$ for $3 \mathrm{~h}$ and $623 \mathrm{~K}\left(0.167 \mathrm{~K} \mathrm{~s}^{-1}\right)$ for $8 \mathrm{~h}$ prior to recording dry sample weight. $\mathrm{N}_{2}$ uptake was recorded between relative pressures of $10^{-7}$ and 1 at $77 \mathrm{~K}$. Total micropore volumes were estimated from linear extrapolation of mesopore $\mathrm{N}_{2}$ uptakes to zero pressure and the density of liquid nitrogen (section S.3 of the Supporting Information).

Solid-state magic angle spinning nuclear magnetic resonance (MAS NMR) spectra were recorded using a Bruker Avance 500 $\mathrm{MHz}$ spectrometer equipped with a $11.7 \mathrm{~T}$ magnet and a Bruker $4 \mathrm{~mm}$ MAS probe. Powdered samples (0.06-0.08 g) were packed into $4 \mathrm{~mm} \mathrm{ZrO}_{2}$ rotors with Kel-F caps and spun at $14 \mathrm{kHz} .{ }^{119} \mathrm{Sn}$ NMR spectra were recorded at an operating frequency of $186.5 \mathrm{MHz}$ and were referenced to $\left(\mathrm{CH}_{3}\right)_{4} \mathrm{Sn}$. Unless otherwise specified, spectra were acquired on hydrated samples, which were exposed to ambient conditions after calcination in flowing air at $853 \mathrm{~K}$ but prior to packing NMR 
Table 1. Site and Structural Characterization of Samples Used in This Study

\begin{tabular}{|c|c|c|c|c|c|}
\hline \multirow[b]{2}{*}{ catalyst } & \multirow[b]{2}{*}{$\mathrm{Si} / \mathrm{Sn}^{b}$} & \multirow[b]{2}{*}{$\mathrm{N}_{2}$ micropore volume ${ }^{c}\left(\mathrm{~cm}^{3} \mathrm{~g}^{-1}\right)$} & \multicolumn{2}{|c|}{${ }^{119}$ Sn MAS NMR resonances ${ }^{a}$ (ppm) } & \multirow[b]{2}{*}{$\mathrm{UV}$-visible band centers ${ }^{d}(\mathrm{~nm})$} \\
\hline & & & hydrated & dehydrated & \\
\hline Sn-Beta & 87 & 0.20 & $-688,-700$ & $-424,-443$ & 203 \\
\hline $\mathrm{SnO}_{2} / \mathrm{Si}$-Beta & 92 & 0.12 & -604 & & 280 \\
\hline $\mathrm{SnO}_{2} / \mathrm{Si}-\mathrm{Beta}-\mathrm{E}$ & 116 & 0.20 & -606 & -602 & 238 \\
\hline $\mathrm{SnO}_{2} / \mathrm{SiO}_{2}$ & 13 & & -605 & & 247 \\
\hline $\mathrm{SnO}_{2}$ & & & -604 & & 276 \\
\hline Si-Beta & & 0.19 & & & n.d. ${ }^{e}$ \\
\hline
\end{tabular}

${ }^{a}$ Relative to $\left(\mathrm{CH}_{3}\right)_{4} \mathrm{Sn} .{ }^{b}$ Determined by electron microprobe. ${ }^{c}$ Determined by extrapolation of mesopore $\mathrm{N}_{2}$ uptakes to zero pressure (Section S.3, Supporting Information). ${ }^{d}$ Diffuse reflectance spectra obtained on materials exposed to ambient conditions. ${ }^{e}$ n.d., not detected

rotors. Selected samples were dehydrated by heating the packed NMR rotors to $423 \mathrm{~K}$ in vacuum and holding overnight prior to acquiring NMR spectra.

Liquid ${ }^{1} \mathrm{H}$ and ${ }^{13} \mathrm{C}$ NMR spectra were recorded using a Varian INOVA $500 \mathrm{MHz}$ spectrometer equipped with an auto$\mathrm{x}$ pfg broad band probe. Proton and carbon chemical shifts are reported relative to the residual solvent signal. ${ }^{1} \mathrm{H}$ NMR spectra were acquired with 256 scans, and ${ }^{13} \mathrm{C}$ NMR spectra were acquired with 1000 scans.

2.3. Reaction Procedures. Reactions with D-glucose (Sigma-Aldrich, $\geq 99 \%$ ) were conducted in $10 \mathrm{~mL}$ thick-walled glass reactors (VWR) that were heated in a temperaturecontrolled oil bath placed on top of a digital stirring hot plate (Fisher Scientific). For each catalyst and solvent combination, different metal/glucose molar ratios were used. Reactions on Sn-Beta in water were typically carried out using $1.0 \mathrm{~g}$ of a $10 \%$ $(\mathrm{w} / \mathrm{w})$ glucose solution and a 1:100 $\mathrm{Sn}$ /glucose molar ratio. Reactions on Sn-Beta in methanol were typically carried out using $1.0 \mathrm{~g}$ of a $1 \%(\mathrm{w} / \mathrm{w})$ glucose solution and a 1:100 Sn/ glucose molar ratio. Reactions on $\mathrm{SnO}_{2} / \mathrm{Si}$-Beta in water and methanol were typically carried out using $1.0 \mathrm{~g}$ of a $1 \%(\mathrm{w} / \mathrm{w})$ glucose solution and a 1:20 Sn/glucose molar ratio. Reactions on $\mathrm{SnO}_{2}-\mathrm{SiO}_{2}$ were performed using $1.5 \mathrm{~g}$ of a $1 \%(\mathrm{w} / \mathrm{w})$ glucose solution and a 1:10 $\mathrm{Sn} /$ glucose molar ratio.

Reactors were placed in the oil bath for specific time intervals and quenched by cooling in an ice bath. Small aliquots were extracted, filtered with $0.2 \mu \mathrm{m}$ PTFE syringe filter, and mixed with D-mannitol (Sigma-Aldrich, $\geq 98 \%$ ) solutions used as an internal standard for quantification $(10 \%(\mathrm{w} / \mathrm{w})$ mannitol for experiments with Sn-Beta in water; $1.5 \%(\mathrm{w} / \mathrm{w})$ mannitol otherwise). Samples were analyzed by high performance liquid chromatography (HPLC) using an Agilent 1200 system (Agilent) equipped with PDA UV $(320 \mathrm{~nm})$ and evaporative light scattering (ELS) detectors. Glucose, fructose, mannose, and mannitol fractions were separated with a Hi-Plex Ca column $(6.5 \times 300 \mathrm{~mm}, 8 \mu \mathrm{m}$ particle size, Agilent $)$ held at 358 $\mathrm{K}$, using ultrapure water as the mobile phase at a flow rate of $0.01 \mathrm{~mL} \mathrm{~s}^{-1}$. Turnover rates were calculated by normalizing the total moles of glucose converted by the total moles of $\mathrm{Sn}$ on each catalyst. For liquid NMR analysis of products formed from isotopic labeling studies using D-glucose-D2 (Cambridge Isotope Laboratories, $\geq 98 \%$ ) and D-glucose- ${ }^{13} \mathrm{C}-\mathrm{C} 1$ (Cambridge Isotope Laboratories, $\geq 98 \%$ ), the glucose, mannose, and fructose fractions were separated by HPLC, isolated by evaporation of $\mathrm{H}_{2} \mathrm{O}$, and dissolved in $\mathrm{D}_{2} \mathrm{O}$ (Cambridge Isotope Laboratories, 99.9\%).

\section{RESULTS AND DISCUSSION}

3.1. Site and Structural Characterization of SnContaining Samples. The X-ray diffractograms of Si-Beta,
Sn-Beta, $\mathrm{SnO}_{2} / \mathrm{Si}$-Beta and $\mathrm{SnO}_{2} /$ Si-Beta-E (Supporting Information Figure S.1) showed patterns that were consistent with the zeolite Beta structure, whereas the XRD pattern of $\mathrm{SnO}_{2} / \mathrm{SiO}_{2}$ (Supporting Information Figure S.1) was consistent with that of an amorphous solid. The XRD pattern of $\mathrm{SnO}_{2} / \mathrm{Si}$ Beta also showed diffraction lines at $2 \theta$ values of $26.7^{\circ}$ and $34.0^{\circ}$ that are characteristic of bulk $\mathrm{SnO}_{2}$ (Supporting Information Figure S.1). The presence of some extracrystalline $\mathrm{SnO}_{2}$ aggregates in the $\mathrm{SnO}_{2} / \mathrm{Si}$-Beta sample (synthesized using $\mathrm{SnO}_{2}$ as the $\mathrm{Sn}$ source) indicates that bulk $\mathrm{SnO}_{2}$ did not completely dissolve or decompose under the hydrothermal conditions used in the synthesis of $\mathrm{SnO}_{2} / \mathrm{Si}$-Beta. The absence of large $\mathrm{SnO}_{2}$ domains (as detectable by XRD) in Sn-Beta and $\mathrm{SnO}_{2} / \mathrm{Si}$-Beta-E indicates that mononuclear $\mathrm{SnCl}_{4}$ precursors did not aggregate significantly during hydrothermal synthesis of Sn-Beta or during the aqueous-phase exchange and subsequent air treatment $(853 \mathrm{~K})$ protocols used to synthesize $\mathrm{SnO}_{2} / \mathrm{Si}$ Beta-E. Indeed, SEM images of the $\mathrm{SnO}_{2} / \mathrm{Si}$-Beta sample, but not of Sn-Beta, showed the presence of large $\mathrm{SnO}_{2}$ particles (Supporting Information Figure S.2).

Total micropore volumes determined from $\mathrm{N}_{2}$ adsorption isotherms (Supporting Information Figures S.3-S.6) are 0.20 and $0.19 \mathrm{~cm}^{3} \mathrm{~g}^{-1}$ for Sn-Beta and Si-Beta, respectively (Table 1). The micropore volume for $\mathrm{SnO}_{2} / \mathrm{Si}$-Beta-E, a sample in which $\mathrm{SnO}_{2}$ was deliberately deposited on the exterior surfaces of Beta crystallites, is also $0.20 \mathrm{~cm}^{3} \mathrm{~g}^{-1}$ (Table 1), consistent with its low Sn content (2.1 wt \%) and the absence of any intracrystalline $\mathrm{SnO}_{2}$ species that may occlude pore volume. In contrast, the micropore volume is $0.12 \mathrm{~cm}^{3} \mathrm{~g}^{-1}$ for $\mathrm{SnO}_{2} / \mathrm{Si}$ Beta (Table 1), which is significantly lower than expected if $\mathrm{SnO}_{2}$ were present as extracrystalline phases or located within intracystralline voids but only occluding space $\left(\sim 0.18 \mathrm{~cm}^{3} \mathrm{~g}^{-1}\right.$; Section S.2, Supporting Information). These data suggest that $\mathrm{SnO}_{2}$ domains located at external crystal surfaces and within the pores of $\mathrm{SnO}_{2} / \mathrm{Si}$-Beta prevent access to a fraction of the internal void space in $\mathrm{SnO}_{2} / \mathrm{Si}$-Beta crystals.

${ }^{119} \mathrm{Sn}$ NMR spectra of Sn-Beta after calcination and exposure to ambient conditions (hydrated) show main resonances centered at -688 and $-700 \mathrm{ppm}$ (Figure 1a). After dehydration, these resonances disappeared, and new resonances appeared concomitantly at -424 and $-443 \mathrm{ppm}$ (Figure $1 \mathrm{~b}$ ), which have been assigned to framework Sn open sites (three framework $-\mathrm{O}(\mathrm{Si})$ bonds and one $(\mathrm{OH})$ group) and framework $\mathrm{Sn}$ closed sites (four framework $-\mathrm{O}(\mathrm{Si})$ bonds), respectively. ${ }^{8}$ The ${ }^{119} \mathrm{Sn}$ NMR spectrum of hydrated $\mathrm{SnO}_{2}$ / $\mathrm{SiO}_{2}$ (Figure 1c) and $\mathrm{SnO}_{2} / \mathrm{Si}$-Beta-E (Figure 1d) samples showed very broad resonances centered near $-604 \mathrm{ppm}$ that did not change upon dehydration (dehydrated $\mathrm{SnO}_{2} /$ Si-Beta-E; Figure 1e). The position of these resonances is consistent with the chemical shift of octahedrally coordinated $\mathrm{Sn}$ in bulk $\mathrm{SnO}_{2}$ 


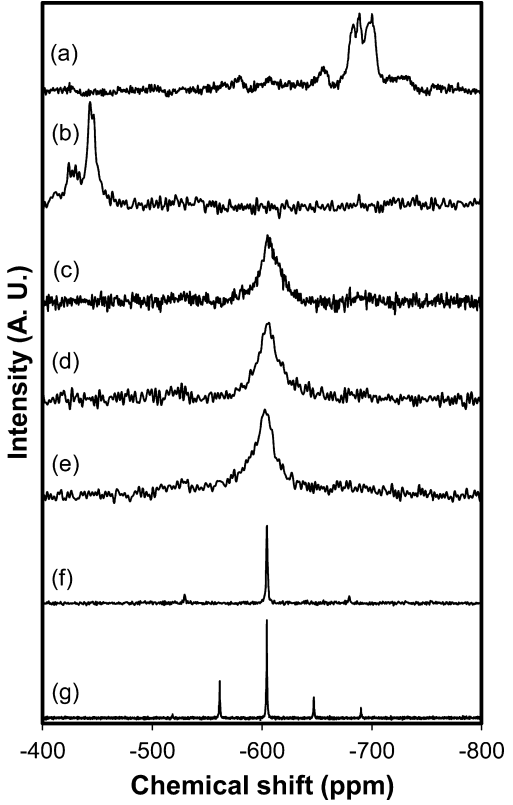

Figure 1. ${ }^{119}$ Sn MAS NMR spectra of (a) Sn-Beta (hydrated), (b) SnBeta (dehydrated), (c) $\mathrm{SnO}_{2} / \mathrm{SiO}_{2}$ (hydrated), (d) $\mathrm{SnO}_{2} / \mathrm{Si}$-Beta-E (hydrated), (e) $\mathrm{SnO}_{2} / \mathrm{Si}$-Beta-E (dehydrated), (f) $\mathrm{SnO}_{2} /$ Si-Beta (hydrated), and (g) bulk $\mathrm{SnO}_{2}$ (hydrated).

(-604.3 ppm; Figure 1g), and their breadth reflects geometric heterogeneities among the octahedral $\mathrm{Sn}$ centers in these samples, as expected from the formation of small $\mathrm{SnO}_{2}$ domains from mononuclear $\mathrm{SnCl}_{4}$ precursors. In contrast with $\mathrm{SnO}_{2} / \mathrm{Si}$ Beta-E and $\mathrm{SnO}_{2} / \mathrm{SiO}_{2}$, the ${ }^{119} \mathrm{Sn}$ NMR spectrum of hydrated $\mathrm{SnO}_{2} / \mathrm{Si}$-Beta (Figure 1f) showed a very sharp resonance at $-604 \mathrm{ppm}$. This sharp resonance reflects the presence of large $\mathrm{SnO}_{2}$ aggregates on $\mathrm{SnO}_{2} /$ Si-Beta, consistent with the diffraction lines for bulk $\mathrm{SnO}_{2}$ that appear in its XRD pattern (Supporting Information Figure S.1) and the large $\mathrm{SnO}_{2}$ particles detected by SEM imaging (Figure S.2).

The DRUV spectrum of Sn-Beta (Figure 2a) showed a peak centered at $203 \mathrm{~nm}$ (Table 1) that has previously been assigned to tetrahedrally coordinated framework $\mathrm{Sn},{ }^{5,16}$ whereas no features were observed in the spectrum of Si-Beta (Figure 2f). The DRUV spectra of $\mathrm{SnO}_{2} / \mathrm{SiO}_{2}$ (Figure $2 \mathrm{~b}$ ) and $\mathrm{SnO}_{2} / \mathrm{Si}$ Beta-E (Figure 2c) showed peaks centered at 247 and $238 \mathrm{~nm}$ (Table 1), respectively, which have been assigned previously to $\mathrm{SnO}_{2}$ species; ${ }^{17-20}$ yet, they also fall in a range $(200-260 \mathrm{~nm})$ assigned to $\mathrm{Sn}$ centers in silicate frameworks that interact with basic molecules (e.g., $\left.\mathrm{H}_{2} \mathrm{O},\left(\mathrm{CH}_{3}\right) \mathrm{CO}, \mathrm{CH}_{3} \mathrm{CN}, \mathrm{CH}_{3} \mathrm{OH}\right){ }^{16}$ The DRUV spectra of bulk $\mathrm{SnO}_{2}$ (Figure 2d) and $\mathrm{SnO}_{2} / \mathrm{Si}$ Beta (Figure 2e) showed very broad bands ranging from 235 to $290 \mathrm{~nm}$ with maxima near $280 \mathrm{~nm}$ (Table 1), which have been assigned to hexacoordinated polymeric Sn species. ${ }^{16}$ Relations between UV-visible absorption wavelengths and the domain sizes of $\mathrm{SnO}_{2}$ nanoparticles have been well-documented; ${ }^{17-20}$ quantum confinement effects cause an increase in the band gap energies (and concomitant decreases in UV-visible absorption wavelengths) of nanoscale semiconducting oxide domains as they decrease in size. These relations would suggest that the lower UV-visible band centers of $\mathrm{SnO}_{2} / \mathrm{SiO}_{2}$ and $\mathrm{SnO}_{2} / \mathrm{Si}$ Beta-E (relative to bulk $\mathrm{SnO}_{2}$ and $\mathrm{SnO}_{2} / \mathrm{Si}$-Beta-E) reflect the presence of smaller $\mathrm{SnO}_{2}$ domains, consistent with the broader $\mathrm{SnO}_{2}$ resonances in their ${ }^{119} \mathrm{Sn}$ MAS NMR spectra (Figure 1).

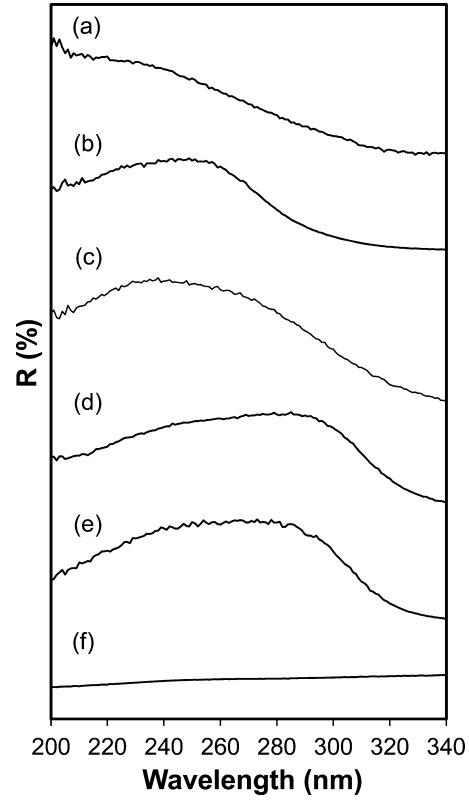

Figure 2. Diffuse reflectance UV-visible spectra of (a) Sn-Beta, (b) $\mathrm{SnO}_{2} / \mathrm{SiO}_{2}$, (c) $\mathrm{SnO}_{2} /$ Si-Beta-E, (d) $\mathrm{SnO}_{2} /$ Si-Beta, (e) bulk $\mathrm{SnO}_{2}$, and (f) Si-Beta.

Taken together, these characterization data indicate that $\mathrm{Sn}$ species are present as framework $\mathrm{Sn}$ sites in Sn-Beta, as extraframework $\mathrm{SnO}_{2}$ particles supported on extracrystalline surfaces of $\mathrm{SnO}_{2} /$ Si-Beta-E or on amorphous surfaces of $\mathrm{SnO}_{2} /$ $\mathrm{SiO}_{2}$, and as extraframework $\mathrm{SnO}_{2}$ particles located both outside and within microporous voids of $\mathrm{SnO}_{2} / \mathrm{Si}$-Beta. This analysis shows clearly that seldom-used ${ }^{119} \mathrm{Sn}$ MAS NMR spectroscopy can unambiguously distinguish framework and extraframework $\mathrm{Sn}$ sites and can also provide inferences about the sizes of extraframework $\mathrm{SnO}_{2}$ domains. In contrast with ${ }^{119}$ Sn MAS NMR spectra, DRUV spectra are used more commonly to characterize $\mathrm{Sn}$ structure but require interpretation of spectral features with more ambiguity and imprecision.

3.2. Glucose Conversion on $\mathrm{Sn}$-Beta and $\mathrm{SnO}_{2}-$ Containing Samples in Water. Fructose was formed as the primary product during differential conversion of glucose on both $\mathrm{Sn}$-Beta and $\mathrm{SnO}_{2} /$ Si-Beta in water. Turnover rates (per mole total $\mathrm{Sn}$ ) were higher on $\mathrm{Sn}$-Beta than on $\mathrm{SnO}_{2} / \mathrm{Si}$-Beta throughout the temperature range studied (343-373 K; see Section S.4, Supporting Information, for all rate data). The apparent activation energy was also higher on Sn-Beta $(93 \pm 15$ $\mathrm{kJ} \mathrm{mol}^{-1}$; Table 2) than on $\mathrm{SnO}_{2} / \operatorname{Si}$-Beta $\left(59 \pm 6 \mathrm{~kJ} \mathrm{~mol}^{-1}\right.$; Table 2). Although both $\mathrm{Sn}-\mathrm{Beta}$ and $\mathrm{SnO}_{2} / \mathrm{Si}$-Beta are able to isomerize glucose to fructose in water, the different structures of framework and extraframework $\mathrm{Sn}$ active sites and the large difference in apparent activation energies between them suggest that different isomerization mechanisms prevail on these two sites.

${ }^{1} \mathrm{H}$ and ${ }^{13} \mathrm{C}$ NMR spectroscopies of products formed from the reaction of a $10 \%(\mathrm{w} / \mathrm{w})$ solution of glucose-D2 over $\mathrm{SnO}_{2} / \mathrm{Si}$-Beta in water $(1 \mathrm{~h}, 373 \mathrm{~K})$ were used to investigate the isomerization mechanism on $\mathrm{SnO}_{2}$ active sites, as was done previously with Sn-Beta in water. ${ }^{6}$ The ${ }^{13} \mathrm{C}$ NMR spectrum of glucose after reaction (Figure 3a) showed resonances at $\delta=$ 74.1 and $71.3 \mathrm{ppm}$ for the C-2 positions of $\beta$-pyranose and $\alpha$ pyranose; their low intensity triplets were also present, reflecting the presence of $\mathrm{D}$ atoms, which disrupt the $\mathrm{NOE}$ 
Table 2. Turnover Rates (373 K) and Apparent Activation Energies $\left(E_{\text {app }}\right)$ for Glucose Isomerization to Fructose and Glucose Epimerization to Mannose on Sn-Beta, $\mathrm{SnO}_{2} / \mathrm{Si}$ Beta and $\mathrm{SnO}_{2} / \mathrm{SiO}_{2}$ in $\mathrm{H}_{2} \mathrm{O}$ and $\mathrm{CH}_{3} \mathrm{OH}$ Solvents

\begin{tabular}{|c|c|c|c|c|c|}
\hline \multirow[b]{2}{*}{ catalyst } & \multirow[b]{2}{*}{ solvent } & \multicolumn{2}{|c|}{$\begin{array}{l}\text { turnover rate }(373 \mathrm{~K}) \\
\left(/ 10^{-3} \mathrm{~mol} \mathrm{~s}^{-1}\right. \\
\left.(\mathrm{mol} \mathrm{total} \mathrm{Sn})^{-1}\right)\end{array}$} & \multicolumn{2}{|c|}{$E_{\text {app }}\left(\mathrm{kJ} \mathrm{mol}^{-1}\right)$} \\
\hline & & fructose & mannose & fructose & mannose \\
\hline Sn-Beta & $\mathrm{H}_{2} \mathrm{O}$ & $27.8 \pm 5.0$ & n.d. ${ }^{a}$ & $93 \pm 15$ & \\
\hline Sn-Beta & $\mathrm{CH}_{3} \mathrm{OH}$ & n.d. ${ }^{a}$ & $7.4 \pm 1.4$ & & $70 \pm 14$ \\
\hline $\begin{array}{c}\mathrm{SnO}_{2} / \mathrm{Si}- \\
\text { Beta }\end{array}$ & $\mathrm{H}_{2} \mathrm{O}$ & $9.7 \pm 1.9$ & n.d. ${ }^{a}$ & $59 \pm 6$ & \\
\hline $\begin{array}{c}\mathrm{SnO}_{2} / \mathrm{Si}- \\
\text { Beta }\end{array}$ & $\mathrm{CH}_{3} \mathrm{OH}$ & $16.6 \pm 2.3$ & n.d. ${ }^{a}$ & $71 \pm 15$ & \\
\hline $\begin{array}{r}\mathrm{SnO}_{2} / \\
\mathrm{SiO}_{2}\end{array}$ & $\mathrm{H}_{2} \mathrm{O}$ & n.d. ${ }^{a}$ & n.d. ${ }^{a}$ & & \\
\hline $\begin{array}{r}\mathrm{SnO}_{2} / \\
\mathrm{SiO}_{2}\end{array}$ & $\mathrm{CH}_{3} \mathrm{OH}$ & $4.2 \pm 0.3$ & n.d. ${ }^{a}$ & $102 \pm 9$ & \\
\hline${ }^{a}$ n.d., not & ected. & & & & \\
\hline
\end{tabular}

of ${ }^{13} \mathrm{C}$ resonances. Thus, the resonance at $\delta=74.1 \mathrm{ppm}$ reflects the presence of $\mathrm{H}$ atoms at some of the glucose $\mathrm{C}-2$ positions, consistent with the low intensity resonances that appear $\sim \delta=$ $3.1 \mathrm{ppm}$ for $\mathrm{H}$ atoms at the $\mathrm{C}-2$ position in the corresponding ${ }^{1} \mathrm{H}$ NMR spectrum (Supporting Information Figure S.7). These data indicate that the D-label on glucose-D2 underwent isotopic scrambling in the presence of $\mathrm{SnO}_{2} / \mathrm{Si}$-Beta in water, as we have previously observed after reaction of glucose-D2 with aqueous $\mathrm{NaOH}$ solutions, but not with $\mathrm{Sn}$-Beta in water (Supporting Information Figure S.8). ${ }^{6}$

The ${ }^{13} \mathrm{C}$ NMR spectrum of fructose products formed from reaction of glucose-D2 with $\mathrm{SnO}_{2} / \mathrm{Si}$-Beta in water (Figure 3c) showed resonances at $\delta=63.8$ and $62.6 \mathrm{ppm}$ for the C-1 position of $\beta$-pyranose and $\beta$-furanose, respectively. The absence of low-intensity triplets for these resonances indicates that no deuterium atoms are bonded to fructose C-1 carbon atoms. ${ }^{6}$ The corresponding ${ }^{1} \mathrm{H}$ NMR spectrum (Supporting Information Figure S.9) shows a resonance at $\delta=3.45 \mathrm{ppm}$ for $\mathrm{H}$-atoms bonded to fructose $\mathrm{C}-1$ carbons, confirming the absence of deuterium at C-1 carbon atoms. In our previous work, ${ }^{6}$ similar NMR results were reported for $\mathrm{NaOH}$-catalyzed glucose-D2 isomerizations. Thus, the current data show that glucose isomerizes on $\mathrm{SnO}_{2}$ via a proton abstraction mechanism analogous to the homogeneous base catalyst, in which fructose is formed via enolate intermediates generated from the base-catalyzed proton abstraction at the $\alpha$-carbonyl carbon (C-2) position of glucose.

Glucose isomerization via reversible enolization proceeds in aqueous alkaline media with activation energies that are nearly twice as large $\left(\sim 120 \mathrm{~kJ} \mathrm{~mol}^{-1}\right)^{21,22}$ as observed on $\mathrm{SnO}_{2} / \mathrm{Si}$ Beta in water $(59 \pm 6$; Table 2$)$. Lower apparent activation energies than expected (by factors of $\sim 2$ ) on $\mathrm{SnO}_{2} /$ Si-Beta would be consistent with internal mass transfer limitations of the reaction rate (details in the Supporting Information, Section S.6). Glucose isomerization rates and activation energies measured on $\mathrm{SnO}_{2} / \mathrm{SiO}_{2}$ and $\mathrm{SnO}_{2} /$ Si-Beta-E, for which diffusion to $\mathrm{SnO}_{2}$ surfaces are not expected to limit rates, were used to assess whether reactions may be transport-limited on $\mathrm{SnO}_{2} / \mathrm{Si}$-Beta. The conversion of $1 \mathrm{wt} \%$ glucose in water mixtures remained below detection limits, however, on $\mathrm{SnO}_{2} /$ $\mathrm{SiO}_{2}, \mathrm{SnO}_{2} /$ Si-Beta-E, and bulk $\mathrm{SnO}_{2}$ (1:50 Sn:glucose molar ratio) after $15 \mathrm{~min}$ at $353 \mathrm{~K}$ (Table 3 ) and on $\mathrm{SnO}_{2} / \mathrm{SiO}_{2}(1: 5$

Table 3. Glucose Conversion to Fructose via Base-Catalyzed Isomerization on $\mathrm{SnO}_{2}$-Containing Samples in $\mathrm{H}_{2} \mathrm{O}$ and $\mathrm{CH}_{3} \mathrm{OH}$ Solvents ${ }^{a}$

\begin{tabular}{lll} 
& \multicolumn{2}{c}{ glucose conversion $(\%)$} \\
\cline { 2 - 3 } catalyst & $\mathrm{H}_{2} \mathrm{O}$ & $\mathrm{CH}_{3} \mathrm{OH}$ \\
$\mathrm{SnO}_{2} / \mathrm{Si}-\mathrm{Beta}$ & 3.0 & 5.0 \\
$\mathrm{SnO}_{2} / \mathrm{Si}-\mathrm{Beta}-\mathrm{E}$ & n.d. ${ }^{b}$ & 3.6 \\
$\mathrm{SnO}_{2} / \mathrm{SiO}_{2}$ & n.d. ${ }^{b}$ & 0.9 \\
$\mathrm{SnO}_{2}$ & n.d. & n.d.
\end{tabular}

${ }^{a}$ Reaction conditions: $1 \%(\mathrm{w} / \mathrm{w})$ glucose solutions, 1:50 metal:glucose ratio, $353 \mathrm{~K}, 15$ min. ${ }^{b}$ n.d., not detected.

Sn/glucose molar ratio), even after $1 \mathrm{~h}$ at $373 \mathrm{~K}$. These data indicate that bulk water inhibits base-catalyzed glucose isomerization on $\mathrm{SnO}_{2}$ surfaces. Thus, we suggest that only $\mathrm{SnO}_{2}$ domains located within hydrophobic zeolite Beta pores, which are protected from contact with bulk liquid water and also present in the $\mathrm{SnO}_{2} / \mathrm{Si}$-Beta sample, can catalyze glucose isomerization in aqueous solvent.

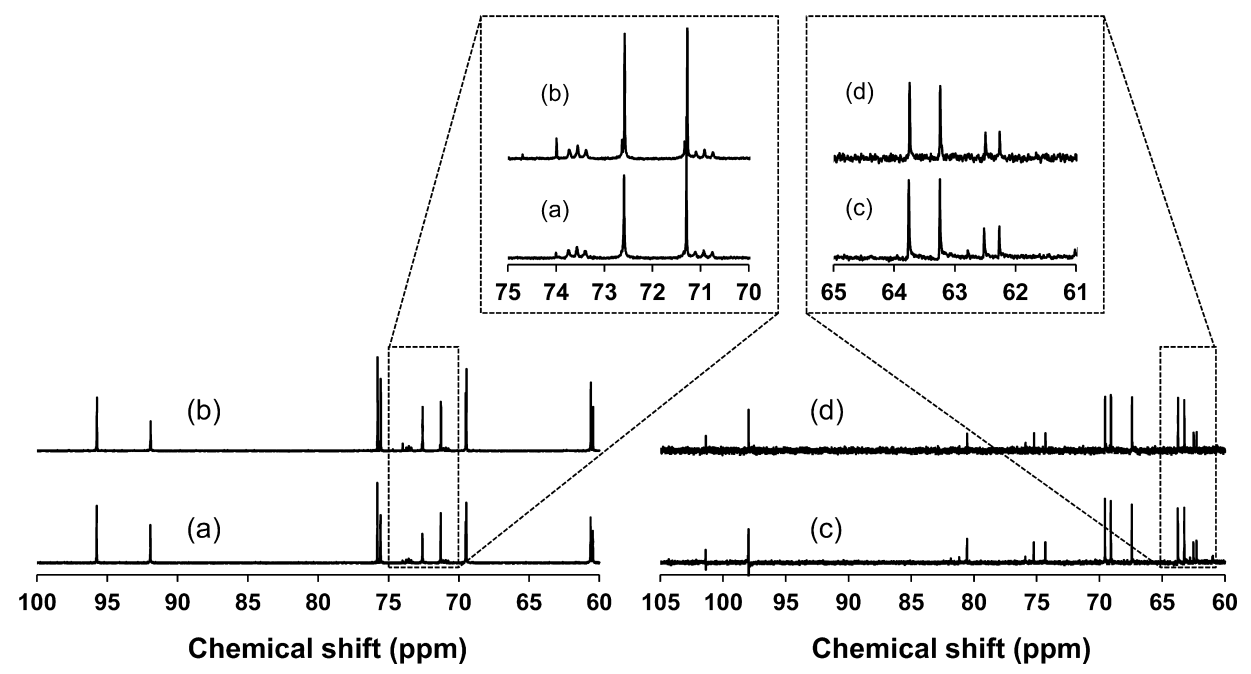

Figure 3. ${ }^{13} \mathrm{C}$ NMR spectra of sugar fractions (glucose or fructose) obtained after reaction of glucose-D2 with $\mathrm{SnO}_{2} / \mathrm{Si}_{-}-\mathrm{Beta}$ in different solvents (water or methanol) at $373 \mathrm{~K}$ for $1 \mathrm{~h}$ : (a) glucose/water, (b) glucose/methanol, (c) fructose/water, and (d) fructose/methanol. 
3.3. Glucose Conversion on $\mathrm{SnO}_{2}$-Containing Samples in Methanol. The differential conversion of $1 \%(\mathrm{w} / \mathrm{w})$ glucose in methanol over $\mathrm{SnO}_{2} / \mathrm{Si}$-Beta formed fructose as the primary product. Turnover rates (per total $\mathrm{Sn}$ ) were higher (by factors of up to $3 ; 333-383 \mathrm{~K}$ ) on $\mathrm{SnO}_{2} / \mathrm{Si}$-Beta in methanol than in aqueous solvent (Supporting Information Table S.1). Glucose also isomerized to fructose on both $\mathrm{SnO}_{2} / \mathrm{SiO}_{2}$ and $\mathrm{SnO}_{2} / \mathrm{Si}$ Beta-E when methanol was used as the solvent (Table 3), in sharp contrast to the undetectable conversion of glucose on these samples in water under equivalent reaction conditions. These data suggest that contact with bulk methanol does not inhibit isomerization reactivity on $\mathrm{SnO}_{2}$ surfaces and, in turn, that the higher turnover rates on $\mathrm{SnO}_{2} / \mathrm{Si}$-Beta in methanol than in water (Supporting Information Table S.1) reflect, to an extent, additional contributions from glucose conversion on extracrystalline $\mathrm{SnO}_{2}$ particles.

In contrast with turnover rates measured over $\mathrm{SnO}_{2} / \mathrm{Si}$-Beta in water, turnover rates over $\mathrm{SnO}_{2} / \mathrm{Si}$-Beta in methanol depended differently on temperature in the $333-363 \mathrm{~K}$ and 363-383 K ranges (Figure 4). This behavior may reflect

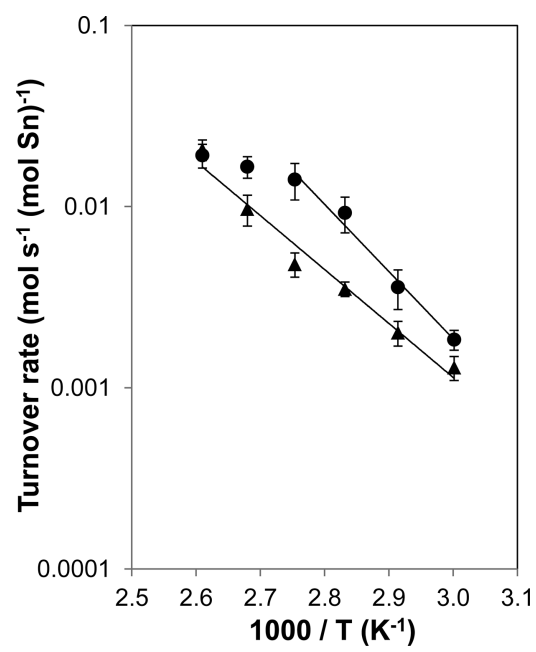

Figure 4. Temperature dependence of turnover rates on $\mathrm{SnO}_{2} / \mathrm{Si}$-Beta for glucose isomerization to fructose in water (triangles) and methanol (circles).

temperature-dependent contributions to measured isomerization rates from $\mathrm{SnO}_{2}$ particles of different sizes and locations (i.e., extracrystalline or intracrystalline). The apparent activation energy estimated from initial rate data in methanol between 333 and $363 \mathrm{~K}$ is $71 \pm 15 \mathrm{~kJ} \mathrm{~mol}^{-1}$, is similar to that determined in water between 343 and $373 \mathrm{~K}\left(59 \pm 6 \mathrm{~kJ} \mathrm{~mol}^{-1}\right.$; Table 2). The activation energy for glucose isomerization to fructose on $\mathrm{SnO}_{2} / \mathrm{SiO}_{2}$ in methanol was $102 \pm 9 \mathrm{~kJ} \mathrm{~mol}^{-1}$ (Supporting Information Figure S.10), which is similar to the values of $\sim 120 \mathrm{~kJ} \mathrm{~mol}^{-1}$ reported for base-catalyzed glucose isomerization in aqueous alkaline media. ${ }^{21,22}$ The lower activation energies on $\mathrm{SnO}_{2} / \mathrm{Si}$-Beta in water and in methanol, compared with $\mathrm{SnO}_{2} / \mathrm{SiO}_{2}$ in methanol, suggest that isomerization rates may, in part, be limited by internal mass transfer restrictions on $\mathrm{SnO}_{2} / \mathrm{Si}$-Beta (section S.6, Supporting Information), as might be expected from the significant decrease in micropore volume accessible to $\mathrm{N}_{2}(\sim 40 \%$; Table 2$)$.

The mechanism of glucose isomerization on $\mathrm{SnO}_{2} /$ Si-Beta in methanol was probed using ${ }^{13} \mathrm{C}$ and ${ }^{1} \mathrm{H}$ NMR spectroscopies of the products formed from the reaction of glucose-D2 reactants, as in the case of $\mathrm{SnO}_{2} / \mathrm{Si}$-Beta in water. Both ${ }^{13} \mathrm{C}$ (Figure $3 \mathrm{~b}$ ) and ${ }^{1} \mathrm{H}$ NMR (Supporting Information Figure S.11) spectra of the glucose after reaction in methanol provided evidence for $\mathrm{H} /$ $\mathrm{D}$ scrambling at the C-2 position. Fructose products did not retain the deuterium label on their $\mathrm{C}-1$ positions, as reflected in resonances present at $\delta=63.8$ and $62.6 \mathrm{ppm}$ in their ${ }^{13} \mathrm{C}$ NMR spectrum (Figure 3d) and at $\delta=3.45 \mathrm{ppm}$ in their ${ }^{1} \mathrm{H}$ NMR spectrum (Supporting Information Figure S.12). These spectral features, which reflect the presence or absence of D-atoms at specific carbon atoms in glucose and fructose products, are similar when glucose is reacted with $\mathrm{SnO}_{2} / \mathrm{Si}$-Beta in methanol and in water.

We conclude from these isotopic labeling studies that $\mathrm{SnO}_{2}$ particles can isomerize glucose to fructose via the basecatalyzed proton abstraction mechanism. Glucose isomerization to fructose on $\mathrm{TiO}_{2}$ and $\mathrm{ZrO}_{2}$ particles has been attributed previously to a base-catalyzed mechanism, but solely based on differences in fructose yields and the numbers of basic sites on these catalysts (determined by $\mathrm{CO}_{2}$ temperature-programmed desorption). ${ }^{23}$ Glucose isomerization in methanol occurs irrespective of $\mathrm{SnO}_{2}$ location within or outside of pore structures, but in water, it apparently requires that $\mathrm{SnO}_{2}$ domains be confined within hydrophobic microporous channels to prevent their contact with bulk liquid water. Although turnover rates (per total $\mathrm{Sn}$ ) were larger by factors of $\sim 3(333-383 \mathrm{~K})$ on $\mathrm{SnO}_{2} /$ Si-Beta in methanol than in aqueous solvent, the order-of-magnitude higher solubility of glucose in water $(\sim 50 \mathrm{wt} \%)$ than in methanol $(\sim 1-2 \mathrm{wt} \%)$ implies that significantly higher yields and productivities can be achieved for glucose isomerization in aqueous media.

3.4. Glucose Conversion on Sn-Beta in Methanol. The differential conversion of glucose on Sn-Beta in methanol led to undetectable rates of fructose formation, an unexpected result considering that fructose was formed with high selectivity under analogous conditions on $\mathrm{Sn}$-Beta in water and on $\mathrm{SnO}_{2} / \mathrm{Si}$-Beta in both water and methanol. Reactions of glucose on Sn-Beta in methanol instead formed mannose as a primary product. Turnover rates (per total $\mathrm{Sn}$ ) for glucose conversion to mannose were factors of $\sim 4$ lower ( $373 \mathrm{~K}$; Table 2 ) and apparent activation energies $\left(70 \pm 14 \mathrm{~kJ} \mathrm{~mol}^{-1}\right.$; Figure 5) were $\sim 23 \mathrm{~kJ} \mathrm{~mol}^{-1}$ lower than those for glucose isomerization to fructose on $\mathrm{Sn}$-Beta in water. Glucose conversion was

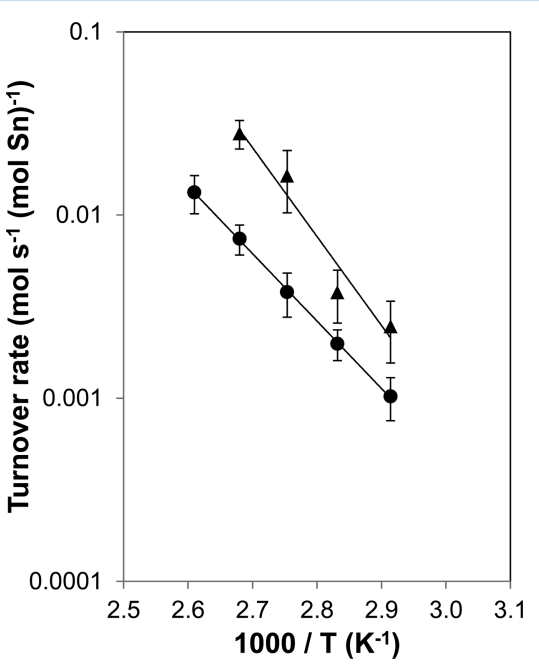

Figure 5. Temperature dependence of turnover rates on Sn-Beta for glucose isomerization to fructose in water (triangles) and epimerization to mannose in methanol (circles). 

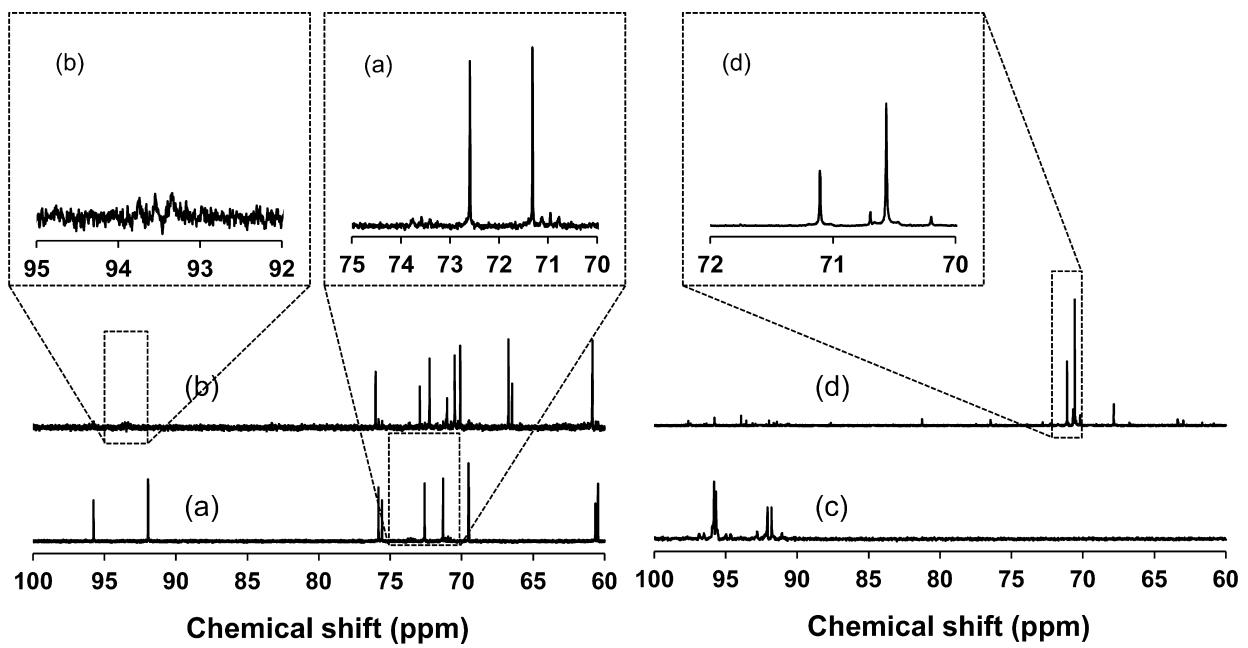

Figure 6. ${ }^{13} \mathrm{C}$ NMR spectra of sugar fractions (glucose or mannose) obtained after reacting different isotopically labeled glucose reactants (glucoseD2 or glucose- ${ }^{13} \mathrm{C}-\mathrm{C} 1$ ) with Sn-Beta in methanol at $373 \mathrm{~K}$ for $4 \mathrm{~h}$ : (a) glucose/glucose-D2, (b) mannose/glucose-D2, (c) glucose/glucose- ${ }^{13} \mathrm{C}-\mathrm{C} 1$, and (d) mannose/glucose- ${ }^{13} \mathrm{C}-\mathrm{C} 1$.

undetectable on Si-Beta after $3 \mathrm{~h}$ at $373 \mathrm{~K}(1 \mathrm{~g}$ of $1 \%(\mathrm{w} / \mathrm{w})$ glucose in methanol solution; $0.01 \mathrm{~g}$ catalyst), indicating that mannose formation is not due to background reactivity on zeolitic silanol groups or in bulk solution. The formation of mannose as an initial product of glucose conversion requires the presence of framework Sn sites and, apparently, methanol instead of water as the solvent.

Mannose is an epimerization product of glucose that can be formed via reversible enolization (Lobry de Bruyn-Alberda van Ekenstein rearrangements) upon abstraction of $\alpha$-carbonyl protons or via an intramolecular exchange of carbon atoms at the C-1 and C-2 positions. ${ }^{24}$ Glucose reactants labeled with ${ }^{13} \mathrm{C}$ at the $\mathrm{C}-1$ position (glucose $-{ }^{13} \mathrm{C}-\mathrm{C} 1$ ) and $\mathrm{D}$ at the $\mathrm{C}-2$ position (glucose-D2) would form mannose products with ${ }^{13} \mathrm{C}$ atoms retained at $\mathrm{C}-1$ but without $\mathrm{D}$ atoms retained at $\mathrm{C}-2$ if by reversible enolization pathways; however, they would form mannose with ${ }^{13} \mathrm{C}$ and $\mathrm{D}$ atoms located at the C-2 and C-1 positions, respectively, if by intramolecular carbon shift steps. Thus, isotopic labeling experiments with glucose-D2 and glucose $-{ }^{13} \mathrm{C}-\mathrm{C} 1$ reactants with $\mathrm{Sn}$-Beta in methanol were performed following the same procedure as with the other samples, but now with longer reaction times $(4 \mathrm{~h})$.

The ${ }^{13} \mathrm{C}$ NMR spectrum of the glucose fraction recovered after reaction of glucose-D2 (Figure 6a) showed only lowintensity triplet resonances at $\delta=74.1$ and $71.3 \mathrm{ppm}$ at the C-2 positions of glucose, indicating that $\mathrm{H} / \mathrm{D}$ scrambling did not occur. The mannose fraction collected after glucose-D2 was reacted over Sn-Beta in methanol (Figure 6b) did not show resonances at $\delta=93.5$ and $93.9 \mathrm{ppm}$, which correspond to the C-1 positions in $\alpha$ and $\beta$ pyranose forms of mannose respectively, indicating that deuterium atoms were located at the $\mathrm{C}-1$ positions of mannose. After reaction of glucose- ${ }^{13} \mathrm{C}-$ C1 reactants, the glucose fraction (Figure 6c) did not show scrambling of the ${ }^{13} \mathrm{C}$ label, but the mannose products (Figure 6d) showed ${ }^{13} \mathrm{C}$ resonances at $\delta=70.5$ and $71.1 \mathrm{ppm}$ corresponding to its C-2 positions. This NMR evidence indicates that, in methanol, framework Sn centers epimerize glucose to mannose by intramolecular carbon skeletal rearrangements and not by reversible enolization.

Fructose was observed as a secondary product when glucose was reacted with $\mathrm{Sn}$-Beta in methanol. The ${ }^{13} \mathrm{C}$ NMR spectrum of the fructose products after reaction of glucose $-{ }^{13} \mathrm{C}-\mathrm{C} 1$ shows the presence of ${ }^{13} \mathrm{C}$ in the $\mathrm{C}-2$ positions (resonances at $\delta$ $=98.0$ and $101.4 \mathrm{ppm}$ ) and the $\mathrm{C}-1$ positions (resonances at $\delta$ $=63.8$ and $62.6 \mathrm{ppm}$ ) of $\beta$-pyranose and $\beta$-furanose, respectively (Supporting Information Figure S.13). These data suggest that fructose is formed at longer times from glucose $\left({ }^{13} \mathrm{C}\right.$ label in $\left.\mathrm{C}-1\right)$ and mannose $\left({ }^{13} \mathrm{C}\right.$ label in $\left.\mathrm{C}-2\right)$, perhaps via enolate intermediates present in minority amounts in solution. In contrast, the ${ }^{13} \mathrm{C} N M R$ spectrum of fructose formed from reactions of glucose $-{ }^{13} \mathrm{C}-\mathrm{C} 1$ with $\mathrm{Sn}$-Beta in water shows ${ }^{13} \mathrm{C}$ located predominantly at $\mathrm{C}-1$ positions (resonances at $\delta=63.8$ and $62.6 \mathrm{ppm}$, Supporting Information Figure S.14), consistent with the hydride-shift isomerization mechanism ${ }^{6}$ that does not involve carbon scrambling in sugar backbones.

The formation of mannose during differential glucose conversion was observed only in the presence of framework $\mathrm{Sn}$ sites and not with extraframework $\mathrm{SnO}_{2}$, suggesting that the structures of framework $\mathrm{Sn}$ active centers are uniquely responsible for epimerization via the carbon shift mechanism. Glucose epimerization was first reported on molybdate anions by Bilik et al.; ${ }^{25,26}$ subsequent isotopic labeling and NMR studies by Hayes et al. ${ }^{27}$ were consistent with the carbon shift mechanism and showed that reactions of mannose- ${ }^{13} \mathrm{C}-\mathrm{C} 1$ on molybdate formed exclusively glucose- ${ }^{13} \mathrm{C}-\mathrm{C} 2$. Lewis acidic metal ion complexes (most notably, $\mathrm{Ni}^{2+}$ diamines), as well as alkaline and rare earth ion based complexes, were later reported by Tanase et al. ${ }^{28-30}$ and London ${ }^{31}$ to also catalyze glucose epimerization to mannose via the carbon shift mechanism. We report here that framework $\mathrm{Sn}$ centers in Sn-Beta also behave as Lewis acid sites that epimerize glucose to mannose via carbon skeletal rearrangements in methanol solvent, consistent with their ability to behave as Lewis acids that isomerize glucose to fructose via intramolecular hydride shifts ${ }^{6,8}$ in aqueous media.

The similar turnover rates for glucose epimerization in methanol and isomerization in water (within a factor of $\sim 2$ at 343-353 K; Supporting Information Table S.1) suggest that both mannose and fructose would have been observed as initial products in either water or methanol solvents if both pathways occurred in parallel. Therefore, the prevalence of epimerization pathways during glucose conversion over Sn-Beta in methanol suggests that methanol, if it could coordinate with framework $\mathrm{Sn}$ active sites, may influence the binding of glucose to such 
sites or the dynamics of elementary steps required for hydride shift isomerization on such sites. Sn and Ti can expand their coordination from 4-fold to 5- or 6-fold when located in silicate frameworks because they have larger covalent radii than $\mathrm{Si}^{32}$ Previous studies have exposed tin silicates to methanol and interpreted changes in DRUV spectra to reflect methanol coordination to framework $\mathrm{Sn}$ closed or open sites, ${ }^{16}$ whereas methanol coordination with framework Ti centers in Ti-zeolites has been detected using X-ray absorption ${ }^{33}$ and in situ UV Raman $^{34}$ studies. Although these findings suggest that methanol can interact with framework Sn sites, ongoing work will investigate further the mechanistic roles of methanol in epimerization on framework $S n$ centers and of water in isomerization on extraframework $\mathrm{Sn}$ sites.

\section{CONCLUSIONS}

In aqueous media, glucose initially undergoes isomerization to fructose on both framework $\mathrm{Sn}$ sites and extraframework $\mathrm{SnO}_{2}$ sites (Scheme 1). Framework Sn centers within the hydro-

Scheme 1. Reaction Network of Glucose with Sn-Beta and $\mathrm{SnO}_{2} / \mathrm{Si}$-Beta in Water and Methanol Solvents ${ }^{a}$

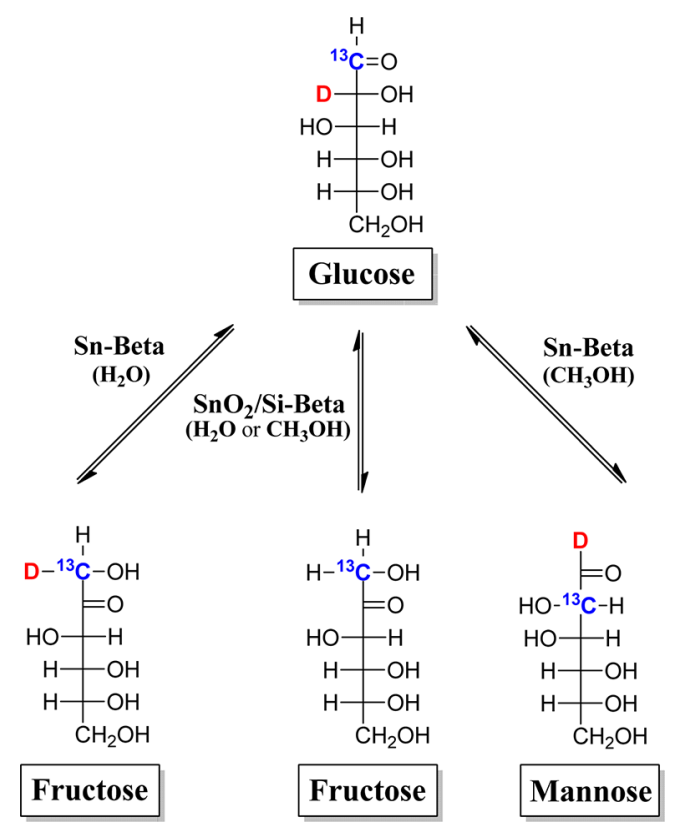

${ }^{a}$ Mechanistic information represented schematically via isotopicallylabeled $\mathrm{D}$ and ${ }^{13} \mathrm{C}$ atoms in reactants and products. Sugars depicted using Fischer projections.

phobic pores of zeolite Beta (Sn-Beta) give ${ }^{119}$ Sn MAS NMR resonances between -685 and $-700 \mathrm{ppm}$ when hydrated but resonances between -425 and -445 ppm when dehydrated. They behave as Lewis acid sites that catalyze isomerization via intramolecular hydride shifts between C-1 and C-2 carbon atoms on acyclic glucose. In contrast, extraframework $\mathrm{SnO}_{2}$ domains give ${ }^{119} \mathrm{Sn}$ MAS NMR resonances at $-604 \mathrm{ppm}$ when hydrated and dehydrated and contain basic sites that catalyze glucose isomerization via the abstraction of protons at C-2 carbon atoms to form enolate intermediates (Scheme 1). Extraframework Sn species appear to be reactive only when confined in hydrophobic zeolite Beta channels $\left(\mathrm{SnO}_{2} / \mathrm{Si}\right.$-Beta $)$ and not when in contact with bulk water at external zeolite crystal surfaces $\left(\mathrm{SnO}_{2} / \mathrm{Si}\right.$-Beta-E $)$ and on amorphous supports
$\left(\mathrm{SnO}_{2} / \mathrm{SiO}_{2}\right)$. These findings demonstrate clearly that the sole observation of glucose-to-fructose isomerization on Sn-zeolite samples, in the absence of isotopic labeling studies and unambiguous methods to characterize $\mathrm{Sn}$ structures (e.g., ${ }^{119}$ Sn MAS NMR spectroscopy), does not provide sufficient evidence for the incorporation of $\mathrm{Sn}$ atoms into zeolite frameworks.

In methanol solvent, glucose is initially epimerized to mannose on framework Sn sites in Sn-Beta via Lewis-acidcatalyzed intramolecular carbon shifts between its C-1 and C-2 positions (Scheme 1). In contrast, $\mathrm{SnO}_{2}$ domains isomerize glucose to fructose in methanol via the identical proton-transfer mechanism that prevails on $\mathrm{SnO}_{2}$ in water (Scheme 1). $\mathrm{SnO}_{2}$ domains are able catalyze glucose isomerization in methanol irrespective of their location within or outside of hydrophobic zeolite Beta pores, indicating that methanol does not inhibit base-catalyzed isomerization on $\mathrm{SnO}_{2}$. Although the mechanistic origin of the effects of methanol on the reactivity of framework Sn centers currently remains unclear, its apparent inhibition of isomerization implies that $\mathrm{Sn}$-containing zeolites that initially convert glucose to fructose in methanol solvent do not contain framework $\mathrm{Sn}$ species.

\section{ASSOCIATED CONTENT}

S Supporting Information

Catalyst characterization (X-ray diffractograms, SEM images, $\mathrm{N}_{2}$ adsorption isotherms), reactant and product identification $\left({ }^{1} \mathrm{H}\right.$ and ${ }^{13} \mathrm{C}$ liquid NMR spectra), and all catalytic rate data are provided. This material is available free of charge via the Internet at http://pubs.acs.org.

\section{AUTHOR INFORMATION}

\section{Corresponding Author}

*E-mail: mdavis@cheme.caltech.edu.

\section{Author Contributions}

${ }^{\dagger}$ R.B.D. and R.G. contributed equally to this work.

Notes

The authors declare no competing financial interest.

\section{ACKNOWLEDGMENTS}

This work was financially supported as part of the Catalysis Center for Energy Innovation, an Energy Frontier Research Center funded by the U.S. Department of Energy, Office of Science, Office of Basic Energy Sciences under Award No. DESC0001004. R.B.D. acknowledges the Obra Social "la Caixa" for a graduate fellowship. We thank Dr. Son-Jong Hwang for the solid-state ${ }^{119} \mathrm{Sn}$ MAS NMR spectra, Dr. David VanderVelde for assistance with the liquid ${ }^{1} \mathrm{H}$ and ${ }^{13} \mathrm{C}$ NMR spectra, Joshua Pacheco for the SEM images, and Carly Bond for experimental assistance with $\mathrm{N}_{2}$ physisorption measurements.

\section{REFERENCES}

(1) Román-Leshkov, Y.; Davis, M. E. ACS Catal. 2011, 1, 15661580.

(2) Corma, A.; Nemeth, L. T.; Renz, M.; Valencia, S. Nature 2001, 412, 423-425.

(3) Corma, A.; Domine, M. E.; Nemeth, L.; Valencia, S. J. Am. Chem. Soc. 2002, 124, 3194-3195.

(4) Corma, A.; Garcia, H. Chem. Rev. 2003, 103, 4307-4365.

(5) Moliner, M.; Román-Leshkov, Y.; Davis, M. E. Proc. Natl. Acad. Sci. U.S.A. 2010, 107, 6164-6168. 
(6) Román-Leshkov, Y.; Moliner, M.; Labinger, J. A.; Davis, M. E. Angew. Chem., Int. Ed. 2010, 49, 8954-8957.

(7) Nikolla, E.; Román-Leshkov, Y.; Moliner, M.; Davis, M. E. ACS Catal. 2011, 1, 408-410.

(8) Bermejo-Deval, R.; Assary, R. S.; Nikolla, E.; Moliner, M.; Román-Leshkov, Y.; Hwang, S.-J.; Pallsdottir, A.; Silverman, D.; Lobo, R. F.; Curtiss, L. A.; Davis, M. E. Proc. Natl. Acad. Sci. U.S.A. 2012, 109, 9727-9732.

(9) Lew, C. M.; Rajabbeigi, N.; Tsapatsis, M. Microporous Mesoporous Mater. 2012, 153, 55-58.

(10) Choudhary, V.; Pinar, A. B.; Sandler, S. I.; Vlachos, D. G.; Lobo, R. F. ACS Catal. 2011, 1, 1724-1728

(11) Taarning, E.; Saravanamurugan, S.; Holm, M. S.; Xiong, J. M.; West, R. M.; Christensen, C. H. ChemSusChem 2009, 2, 625-627.

(12) Holm, M. S.; Saravanamurugan, S.; Taarning, E. Science 2010, $328,602-605$.

(13) Osmundsen, C. M.; Holm, M. S.; Dahl, S.; Taarning, E. Proc. $R$. Soc. A 2012, 468, 2000-2016.

(14) Lew, C. M.; Rajabbeigi, N.; Tsapatsis, M. Ind. Eng. Chem. Res. 2012, 51, 5364-5366.

(15) Kovalevsky, A. Y.; Hanson, L.; Fisher, S. Z.; Mustyakimov, M.; Mason, S. A.; Forsyth, V. T.; Blakeley, M. P.; Keen, D. A.; Wagner, T.; Carrell, H. L.; Katz, A. K.; Glusker, J. P.; Langan, P. Structure 2010, 18, 688-699.

(16) Mal, N. K.; Ramaswamy, A. V. J. Mol. Catal. A: Chem. 1996, 105, 149-158.

(17) Bhagwat, M.; Shah, P.; Ramaswamy, V. Mater. Lett. 2003, 57, 1604-1611.

(18) Chiodini, N.; Paleari, A.; DiMartino, D.; Spinolo, G. Appl. Phys. Lett. 2002, 81, 1702-1704.

(19) Gu, F.; Wang, S. F.; Song, C. F.; Lu, M. K.; Qi, Y. X.; Zhou, G. J.; Xu, D.; Yuan, D. R. Chem. Phys. Lett. 2003, 372, 451-454.

(20) Pang, G. S.; Chen, S. G.; Koltypin, Y.; Zaban, A.; Feng, S. H.; Gedanken, A. Nano Lett. 2001, 1, 723-726.

(21) Kooyman, C.; Vellenga, K.; Dewilt, H. G. J. Carbohydr. Res. 1977, 54, 33-44.

(22) Vuorinen, T.; Sjostrom, E. Carbohydr. Res. 1982, 108, 23-29.

(23) Watanabe, M.; Aizawa, Y.; Iida, T.; Nishimura, R.; Inomata, H. Appl. Catal., A 2005, 295, 150-156.

(24) Osanai, S. Top. Curr. Chem. 2001, 215, 43-76.

(25) Bilik, V.; Petrus, L.; Farkas, V. Chem. Zvesti 1975, 29, 690-696.

(26) Bilik, V.; Petrus, L.; Zemek, J. Chem. Zvesti 1978, 32, 242-251.

(27) Hayes, M. L.; Pennings, N. J.; Serianni, A. S.; Barker, R. J. Am. Chem. Soc. 1982, 104, 6764-6769.

(28) Tanase, T.; Shimizu, F.; Kuse, M.; Yano, S.; Yoshikawa, S.; Hidai, M. J. Chem. Soc., Chem. Commun. 1987, 659-661.

(29) Tanase, T.; Shimizu, F.; Kuse, M.; Yano, S.; Hidai, M.; Yoshikawa, S. Inorg. Chem. 1988, 27, 4085-4094.

(30) Tanase, T.; Shimizu, F.; Yano, S.; Yoshikawa, S. J. Chem. Soc., Chem. Commun. 1986, 1001-1003.

(31) London, R. E. J. Chem. Soc., Chem. Commun. 1987, 661-662.

(32) Camblor, M. A.; Corma, A.; Perez-Pariente, J. Zeolites 1993, 13, $82-87$.

(33) Davis, R. J.; Liu, Z.; Tabora, J. E.; Wieland, W. S. Catal. Lett. 1995, 34, 101-113.

(34) Wang, L. L.; Xiong, G.; Su, J.; Li, P.; Guo, H. C. J. Phys. Chem. C 2012, 116, 9122-9131. 